\title{
INVESTIGATION OF THROTTLING CHARACTERISTICS IN SUPERSONIC POLYCLINIC INLET
}

\author{
D.A. Vnuchkov \\ V.I. Zvegintsev \\ D.G. Nalivaichenko
}

vnuchkov@itam.nsc.ru

zvegin@itam.nsc.ru

denis@itam.nsc.ru

Khristianovich Institute of Theoretical and Applied Mechanics, Siberian Branch of Russian Academy of Sciences, Novosibirsk, Russian Federation

\begin{abstract}
This paper presents an experimental investigation of throttling characteristics of a multi-wedge air inlet of a wind tunnel built for flat flow field at $\mathrm{M}=2.5$. The experiments were performed in a wind tunnel at $\mathrm{M}$ numbers of 2.55, 3.05 and 4.05. Results of numerical simulation of the flow in the air inlet, where air flow restriction was implemented by additional heating of the flow in the channel past the air inlet, are given for comparison. Experimental throttling characteristics are in good agreement with the values obtained from computations
\end{abstract}

\author{
Keywords \\ Multi-wedge air inlet, throttling \\ characteristics, aerodynamic \\ experiment, numerical simulation
}

Introduction. Air inlets are used in a jet engine for deceleration of the incoming airflow and reduction of its Mach number (up to subsonic values) for the air taken into the combustion chamber of the engine. Ensuring efficient functioning of the air inlet for all expected flight parameters is an important task which shall be solved during the design of any jet engine, incl. a ramjet [1]. ITAM SB RAS first started the gas-dynamic design of three-dimensional air inlets based on the combination of well-known two-dimensional flows in the 1970s [2, 3]. Simple analytical methods can be used to obtain the characteristics of the air inlets presented in this paper for their target modes of operations, which makes the design and preliminary analysis of new air inlets much easier. However, for other possible modes of operation, the air flow becomes 3-dimensional, therefore requiring 3-dimensional computational methods of analysis.

Papers $[4,5]$ present design and geometry of a novel frontal air inlet. It is symmetrical around its central axis. Its central body is multi-wedged (star-shaped cross-section). The same papers present the results for the first tests on the air inlet. Its target Mach number is $\mathrm{M}=4$. The tests were performed in a short-term action MAF testbed with $\mathrm{M}=2.85, \mathrm{M}=3.83$, and $\mathrm{M}=4.95$; angle of attack $\alpha=0$, $3,6,9^{\circ}$. 
D.A. Vnuchkov, V.I. Zvegintsev, D.G. Nalivaichenko

This paper presents a similar multi-wedge air inlet with target Mach number of $\mathrm{M}=2.5$. The tests were performed in a wind tunnel providing stationary (intermittent) airflow, which allowed implementation of a specific measurement method, providing continuous throttling characteristics data and increasing the accuracy of the results.

Measurement conditions. Air inlet model description. The geometry of the model in question is shown on the Fig. 1. The air inlet is optimized for the Mach number of the general stream equal to $\mathrm{M}=2.5$. The model consists of a central body, in turn consisting of eight $\mathrm{V}$-shaped sectors (Fig. 1), with the generating wedge's angle of $\theta=15^{\circ}$. A cylinder-shaped cowl is fixed on the lateral wedges of the central body. The inner diameter of this cylinder is $80 \mathrm{~mm}$, and therefore the inlet area is equal to $5026 \mathrm{~mm}^{2}$. The cowl is followed by a divergent cone, it's opening half-angle is $\theta=15^{\circ}$. This cone is connected to a cylinder with the diameter of $116 \mathrm{~mm}$. The length of this cylinder is $39 \mathrm{~mm}$, the area of its base is $3455 \mathrm{~mm}^{2}$, amounting $69 \%$ of the inlet entrance area. The external body of the cowl repeats the geometry of the internal flow. The diameter of the cowl is $122 \mathrm{~mm}$, while its wall's width is $3 \mathrm{~mm}$.
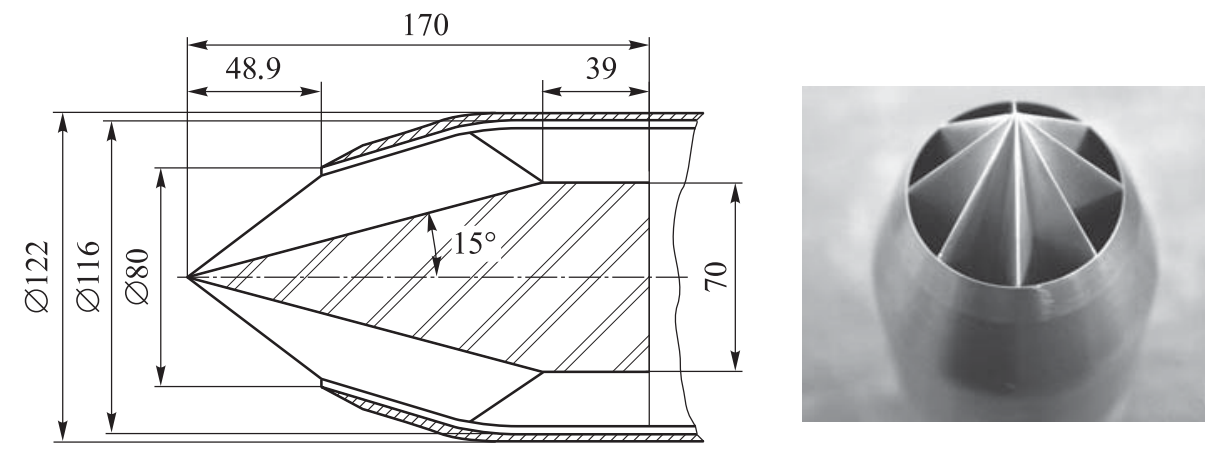

Fig. 1. Scheme of the multi-wedge frontal air inlet

Experiment setup. The experiment was performed in T-313 wind tunnel of the ITAM SB RAS. T-313 wind tunnel (Fig. 2) is an intermittent action facility providing Mach numbers in the range of 1.75 to 7 . There is a set of interchangeable nozzles allowing the variation of Mach numbers with a step of $0.25-1$ depending on the required speed range.

The test chamber has a rectangular cross-section $(0.6 \times 0.6 \times 2 \mathrm{~m}$ in size $)$. The test chamber is located inside the so-called "pressure chamber", hosting the mechanics required for the control of attack angle and the floating rim of the aerodynamic balances. It is possible to set the angles of attack in the range $\alpha=-4 \ldots 22^{\circ}$. Supersonic diffusor, two ejectors and silencer are located behind the test chamber in the order of the listing. 


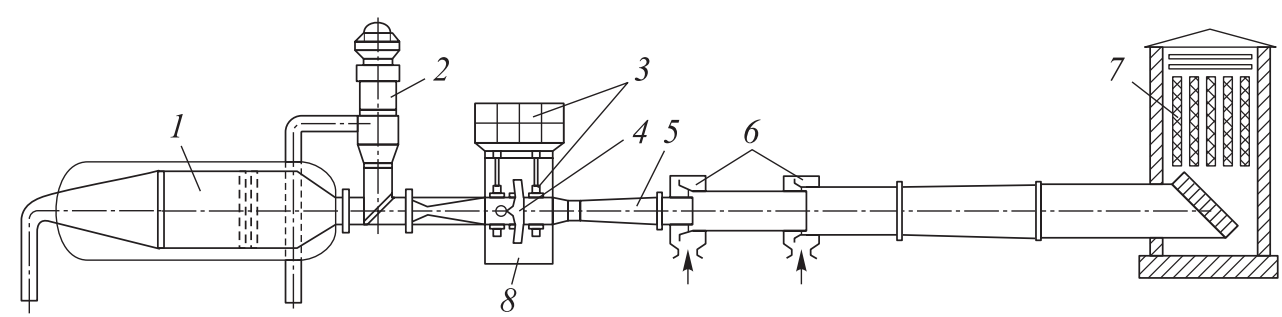

Fig. 2. Sketch of the T-313 wind tunnel of ITAM SB RAS:

1 is fore-chamber; 2 is heater; 3 is aerodynamic scales; 4 is test chamber; 5 is supersonic diffusor; 6 is ejectors; 7 is noise-cancellation shaft; 8 is pressure chamber

One run of the T-313 wind tunnel lasts from 3 to 10 minutes, depending on the operation mode. The air is supplied from gas tanks, each at 1.8 MPa pressure. The gas tanks are filled with air by a turbine compressor station. The two ejectors and the maximum allowed total flow stagnation pressure of $1.6 \mathrm{MPa}$ allows the Reynolds number to be varied in the range of $\operatorname{Re}=(5 \ldots 70) \cdot 10^{6}$.

Flow-meter and throttle. A flow-meter/throttle was used for measurement. It was used for measuring the flow on the air inlet output, and for throttling of this flow. The scheme of this device is shown on Fig. 3.

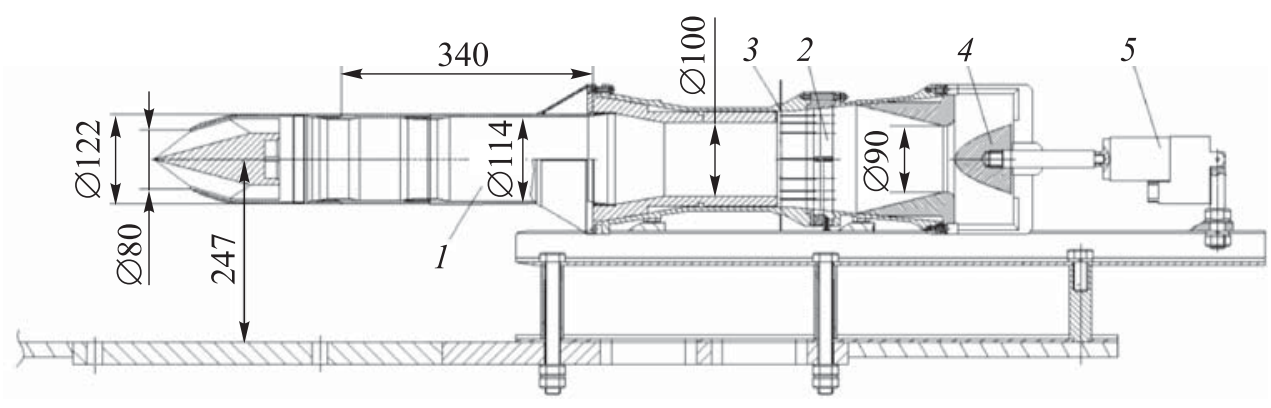

Fig. 3. Flow-meter/throttle device:

1 is settling settling chamber; 2 is measurement section with a comb of Pitot pressure gauges;

3 is holes for static pressure measurement; 4 is blocking cone; 5 is electric motor

The air inletinlet under test is first being connected to the flow measurement device. The air caught by the air inlet then reaches the settling chamber 1 (its diameter is $114 \mathrm{~mm}$ ). The following part is a cone where the diameter decreases to $100 \mathrm{~mm}$. After this cone, there is a measurement section 2, also having a diameter of $100 \mathrm{~mm}$, length $145 \mathrm{~mm}$. The diameter of measurement chamber is constant. The measurement section features Pitot pressure gauges placed equidistantly on the rings mounted at the measurement (control) cross-section. The walls at the measurement (control) cross-section also have 3 holes for measurement of static pressure. 
D.A. Vnuchkov, V.I. Zvegintsev, D.G. Nalivaichenko

After the measurement cross-section, the blocking cone 4 is installed. The cone may be moved along the wind tunnel's axis using, propelled by an electric motor 5. The required displacement of the cone (ca. $72 \mathrm{~mm}$ ) is being set up before the experimental run, using the terminal switches in the motor's power supply. Setting the displacement of the cone changes the output area $\left(A_{\text {out }}\right)$ of the measurement device channel. The output area changes from 0 to $6400 \mathrm{~mm}^{2}$ (the output diameter is $90 \mathrm{~mm}$ ). The ratio of the output area to the measurement chamber area $A_{\text {out }} / A_{m c}$ can therefore be changed in the range from 0 to 0.81 $\left(A_{m c}=7854 \mathrm{~mm}^{2}\right.$, measurement chamber diameter is equal to $\left.100 \mathrm{~mm}\right)$. Usually, during an experimental run the blocking cone was moved forward (i.e., output area was reduced) till surging occurred on the air inlet input, and then the cone was moved backward (i.e., output area was increased). Our experimental runs employed a new method for throttling, where the blocking cone was being continuously moved during the experimental run with the velocity of $1.6 \mathrm{~mm} / \mathrm{s}$. The pressures measured in the measurement chamber were registered using a rapid registration system capable of the registration of up to 500 data points per second.

The throttling device and air inlet model are installed in the test chamber. They are fixed using supports connecting them to the lower wall of the chamber. The attack angle was chosen to be $\alpha=0$ throughout all test runs and was not changed.

Many years of experience in the research of inhomogeneity of the field of air flow velocities has shown that the mean square deviation for Mach numbers in the test chamber don't exceed $0.5 \%$ at $\mathrm{M}=2-4$. The measurement error for deceleration parameters don't exceed $0.1-0.3 \%$, the angle of attack is measured with an error not worse than $\pm 0,05^{\circ}$, and the free turbulence does not exceed $0.2-0.4 \%$.

Table 1 below presents the flow parameters for T-313 wind tunnel of the ITAM SB RAS characterizing the experiment runs.

Table 1

Typical experimental condition for testing of a mult-wedge air inlet via T-313 wind tunnel

\begin{tabular}{|c|c|c|c|c|}
\hline Experimental run ID & $\mathrm{M}$ & $P_{0}, \mathrm{MPa}$ & $T_{0}, \mathrm{~K}$ & $\mathrm{Re}$ \\
\hline 4168 & 4.05 & 1.05 & 288 & $50.5 \cdot 10^{6}$ \\
\hline 4171 & 3.05 & 0.463 & 278 & $38.1 \cdot 10^{6}$ \\
\hline 4176 & 2.55 & 0.352 & 282 & $36.6 \cdot 10^{6}$ \\
\hline
\end{tabular}

The air inlet was tested using the flow-meter/throttling device at the nominal Mach numbers of $\mathrm{M}=2.55,3.05,4.05$ with no heating of the air flow. 
Experimental design and error estimation for throttling parameters. There is a well-known method for aerodynamic model testing of the air inlet using stationary wind tunnels at high supersonic flow velocities $(M \geq 2)$. Specifics of the method are described in papers [6-9]. According to this method, the supersonic flow is being decelerated down to low sub-sonic velocities in the settling chamber 1 (Fig. 3) of the flow-through channel of the flow-meter/throttling device. Then, the flow is measured as well as the total pressure of the passing air. The throttling characteristic of the air inlet is the dependence between the coefficient of total pressure recovery (stagnation pressure) recovery and the flow rate coefficient, measured under the changing counter-pressure values in the area behind the air inlet.

When the counter-pressure changes due to active throttling of the output section of the channel, the characteristics of flow through the air inlet also change. Usually that involves a significant change in the flow coefficient, while the total pressure recovery coefficient almost doesn't change. Increased throttling moves the normal shock into the area in front of the input cross-section of the air inlet's cowl, which can cause surging of the air inlet.

Total pressure recovery coefficient is the ratio of the pressure measured by the comb of total pressure gauges in the measurement section to the stagnation pressure of the approach flow. The stagnation pressure error measured in T-313 wind tunnel does not exceed $0.1 \%$. The stagnation pressure change due to wind tunnel control system operation is 1-2 \% during one experimental run. The actual values of the stagnation pressure where measured on-line with the model characteristics measurement, i. e., the slow changes of the stagnation pressure were accounted for.

The static pressure was measured using eight sensors installed in the measurement section of the flow-meter of the model. Each sensor employed TDM2-A pressure sensing unit capable of the measurement range between 0 and 1.6 bar. According to its data sheet, the measurement precision of each sensor is $0.1 \%$. Our experience shows that the inhomogeneity of the static pressure in the measurement section (the deviation of the values provided by individual sensors from the mean value of data from all sensors) does not exceed $1 \%$. Considering the irregularities of individual sensor calibration, errors of data registration and other systems, we assume the error of the individual pressure sensor to be $0.5 \%$.

The error of the flow measurement depends on the precision of the measurement of the ttoal and the static pressures in the measurement section, and also on the absolute value of the flow velocity (Mach number) in this section [10]:

ISSN 0236-3941. Вестник МГТУ им. Н.Э. Баумана. Сер. Машиностроение. 2019. № 2 


$$
\left.\delta\left(\mathrm{M}_{c}\right)=\left(\delta\left(P_{c}\right)+\delta\left(P_{0}\right)\right) / F\left(\mathrm{M}_{c}\right)\right)
$$

where $F\left(\mathrm{M}_{c}\right)=\chi \mathrm{M}_{c}^{2} /\left(1+(\chi-1) \mathrm{M}_{c}^{2} / 2\right), \chi$ - adiabatic index.

The value $F\left(\mathrm{M}_{c}\right)$ decreases significantly for lower Mach numbers, which in turn drives the increase of the Mach number measurement error. The minimum Mach number observed during our experiments on the measurement comb was $\mathrm{M}_{c}=0.4$, which yields $F\left(\mathrm{M}_{c}\right)=0.2$. Therefore, $\delta\left(\mathrm{M}_{c}\right)=\left(\delta\left(P_{c}\right)+\delta\left(P_{0}\right)\right) / F\left(\mathrm{M}_{c}\right)=$ $=(0.002+0.002) / 0.2=0.02=2 \%$.

Once the Mach number measurement error is known, flow rate measurement error can be calculated using the formula:

$$
\delta(\rho W)=\left(1-\frac{(1+\chi) \mathrm{M}_{c}^{2}}{2\left(1+\frac{\chi-1}{2} \mathrm{M}_{c}^{2}\right)}\right) \delta\left(\mathrm{M}_{c}\right)+\delta\left(P_{0}\right) .
$$

Therefore $\delta(\rho W)=0.81 \cdot 0.02+0.02=0.036=3.6 \%$.

The flow rate coefficient $\varphi$ of the air inlet is the ratio of the flow rate through the measurement section to the maximum possible air flow rate through the intake section of the air inlet $G_{0}$

$$
\varphi=G(t) / G_{0} .
$$

The area of the intake section of the air inlet is defined as the area of a figure formed by the projections of the forward edges of the air inlet on a plane perpendicular to the air inlet's axis. The precision of the oncoming air flow measurement is ca. $1 \%$. Therefore, the error of the flow rate coefficient measurement amounts $\delta(\varphi)=4.6 \%$.

The total pressure was measured using nine Pitot pressure gauges placed in the measurement section of the flow-meter. Each gauge of the comb employed an TDM2-A pressure sensor with the measurement range of 0 to 6 bar. The data sheet provided precision value for the sensor is $0.1 \%$. The experience with the experimental results processing shows that, for each data point, the deviation of each sensor's measurement from the average of all sensors' measurements did not exceed $\delta\left(P_{0}\right)=2 \%$. Considering the irregularities of individual sensor calibration, errors of data registration and other systems, we assume the error of the individual pressure sensor to be $0.5 \%$.

The precision of the oncoming flow measurement is $0.2 \%$. Therefore, the precision of the determination of recovery coefficient for the total pressure in the experiments in question does not exceed $\delta(\sigma)=0.5 \%$. 
Experimental results. Figure 4 presents typical shadowgraphies of the flow on the input part of the poly-wedge air inlet.
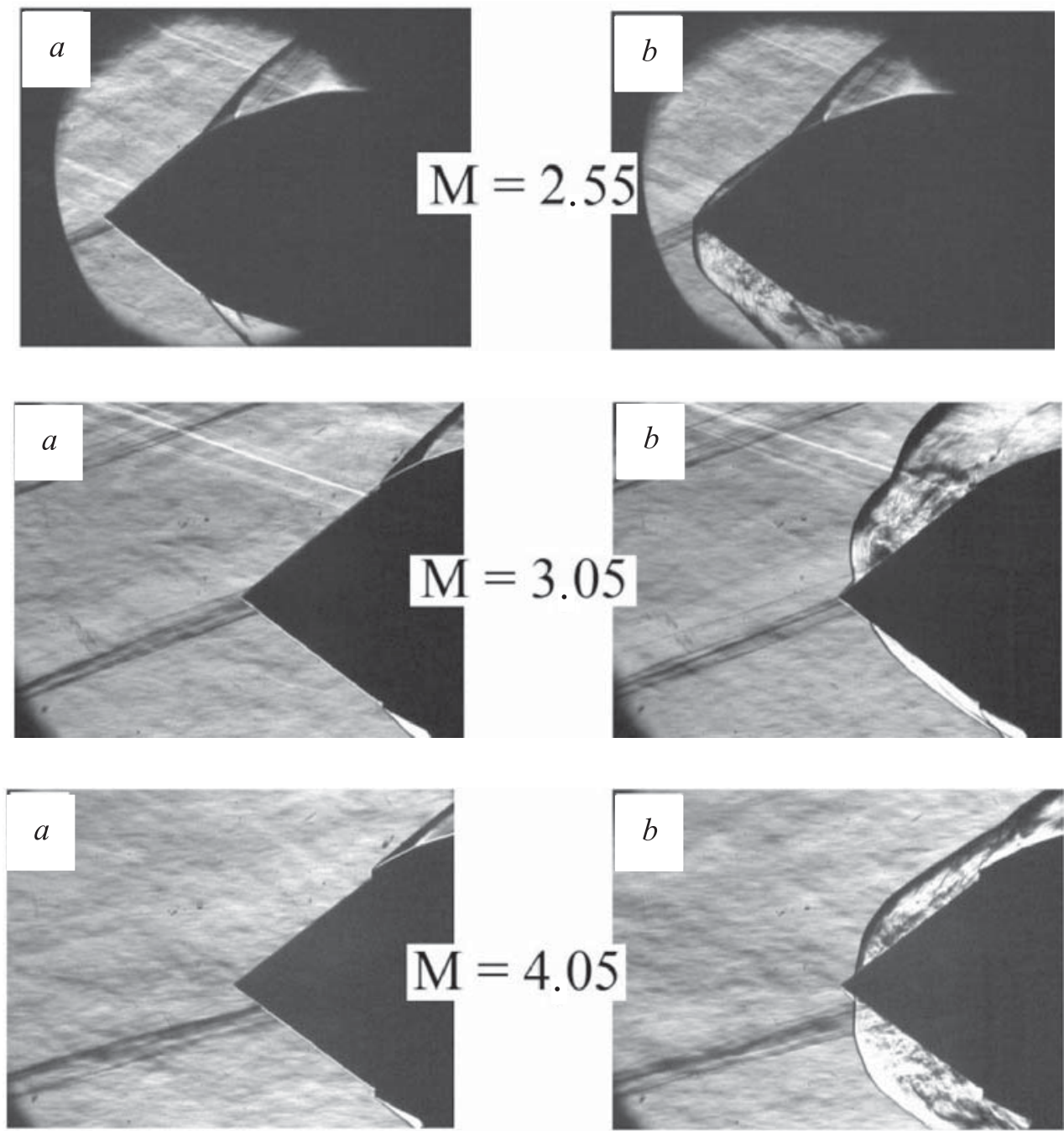

Fig. 4. Shadowgraphies of the flow in the intake area of the multi-wedge air inlet $a$ are stable intake mode; $b$ are surging

Figure 5 presents typical graphs for averaged total and static pressure measured at the measurement section of the air inlet. For each experimental run, just after the flow was stabilized, blocking system motor was turned on, which moved the blocking cone forward (i.e., closing the inlet). The system of shockwaves established in the flow-meter's channel thus moved forward towards the entrance of the inlet, due to increasing counter-pressure. The flow velocity before pseudo-shock decreased and the losses of the total pressure related to the 
D.A. Vnuchkov, V.I. Zvegintsev, D.G. Nalivaichenko
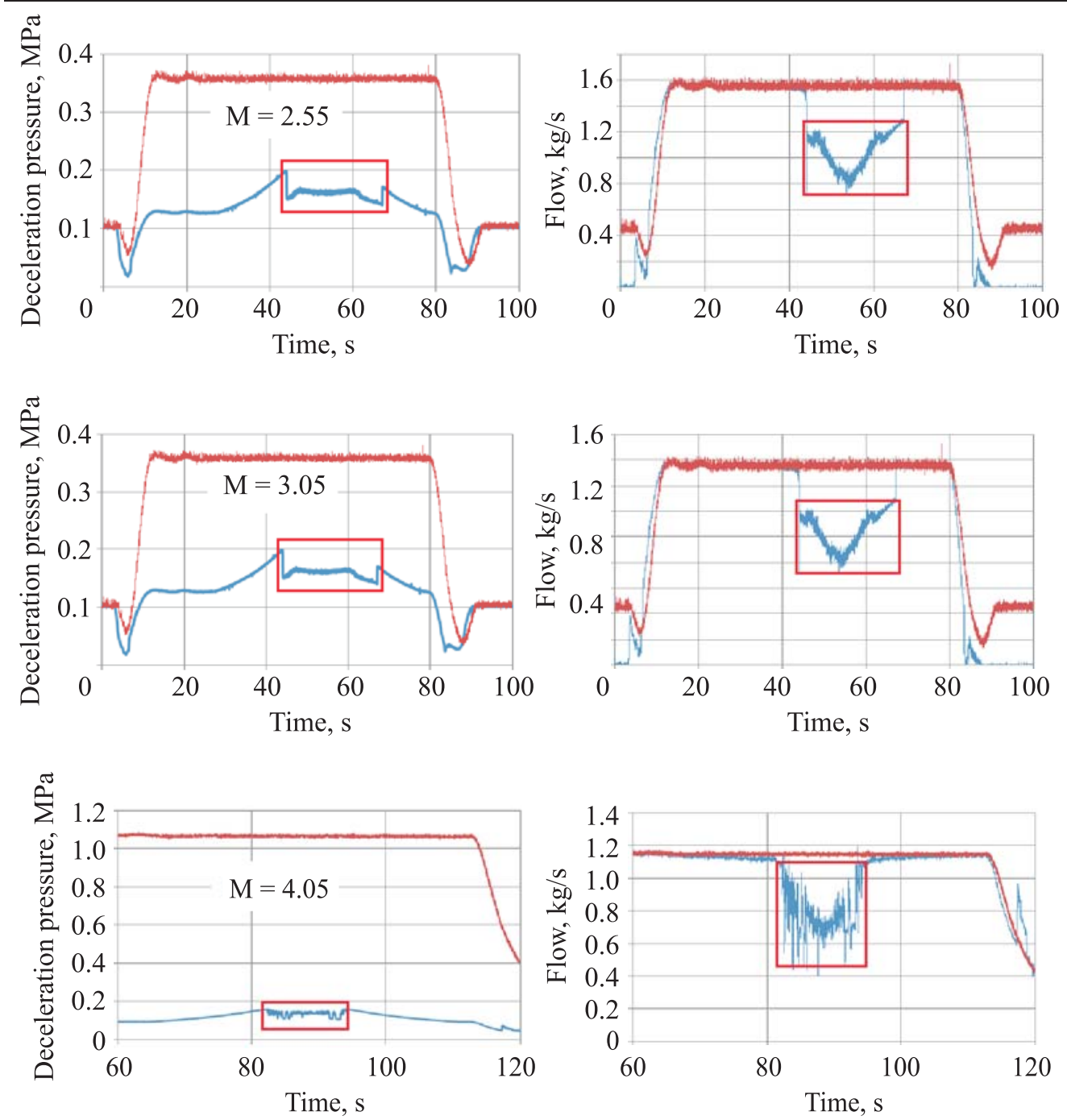

Fig. 5. Measurement of the flow rate and total pressure in the measurement section of the flow-meter. Multi-wedge air inlet testing

trans-sonic transition decreased as well. This situation can be seen on the total pressure graphs, as the measurements are taken under constant approach flow pressure. At a point, the shockwaves transition through the entrance part of the inlet, thus disrupting the intake flow of the air inlet. This is the surging mode of operation of the inlet. It can be seen on the shadowgraphs. Total pressure in this mode decreases significantly and becomes highly unstable. The surging is highlighted on Fig. 5 using a rectangular frame. After the surging happened, we switched the direction of the blocking cone's movement, and the throttle begun moving towards the exit of the flow-meter device. At a point, surging disappeared and the flow in the inlet restored. As the throttle was opened, the 
shockwaves moved back from the inlet, due to reduction of the counter-pressure. Flow velocity increased and total pressure after trans-sonic transition decreased.

Fig. 5 shows that surging and flow recovery on the entrance of the air inlet happens at different blocking cone displacements both for $\mathrm{M}=2.55$ and $\mathrm{M}=3.05$. It can be concluded that the air inlet under test features hysteresis property, and the processes of surging and flow recovery differ. At $M=4.05$ there was no hysteresis even when the blocking cone was in the "fully closed" position. In this case, both the shadowgraphs and calculation show that the channel is not being closed.

On the right-hand side of the Fig. 5 the red curve shows the flow measurement on the entrance of the air inlet (calculated based on the known parameters of the approach flow and geometric parameters of the cowl). The blue line shows the data of the flow measurement in the flow-meter system. It is shown that, for the multi-wedge air intake under consideration, the flow in the measurement section remains practically constant despite the constantly changing throttle displacement. Only during the surging mode, the flow in the measurement section significantly decreases and becomes unstable. This fact shows that a significant part of the approach flow does not go into the inlet. When the blocking cone is moved back, at a point the surging mode ends and the flow in the measurement section restores.

Numerical simulation. The object of simulation was a ramjet equipped with a multi-wedge air inlet, installed on an aerial vehicle flying at the altitude of $0.87 \mathrm{~km}$ with the velocities of $\mathrm{M}=2.5,3,4$ (Table 2). The throttling characteristics of the air inlet were changed because of heating of the air flow in the combustion chamber producing input power from 0 to $40 \mathrm{MW}$, corresponding to enthalpy change $I_{\text {out }} / I_{\text {in }}$ in the range of 1 to 7 .

Table 2

The modelled flight parameters for numerical simulation of the multi-wedge air inlet

\begin{tabular}{|c|c|c|c|c|}
\hline $\mathrm{M}$ & Altitude, $\mathrm{km}$ & $P_{0}, \mathrm{MPa}$ & $T_{0}, \mathrm{~K}$ & $\mathrm{Re}$ \\
\hline 4 & 0.87 & 14.1 & 1186 & $36.6 \cdot 10^{6}$ \\
\hline 3 & 0.87 & 3.4 & 791 & $38.1 \cdot 10^{6}$ \\
\hline 2.5 & 0.87 & 1.6 & 636 & $50.5 \cdot 10^{6}$ \\
\hline
\end{tabular}

The numerical simulation was performed using a software complex consisting of SolidWorks and ANSYS modelling system. The 3D model of the air inlet was first prepared in SolidWorks, then it was exported into ANSYS where the aerodynamic calculations took place. 

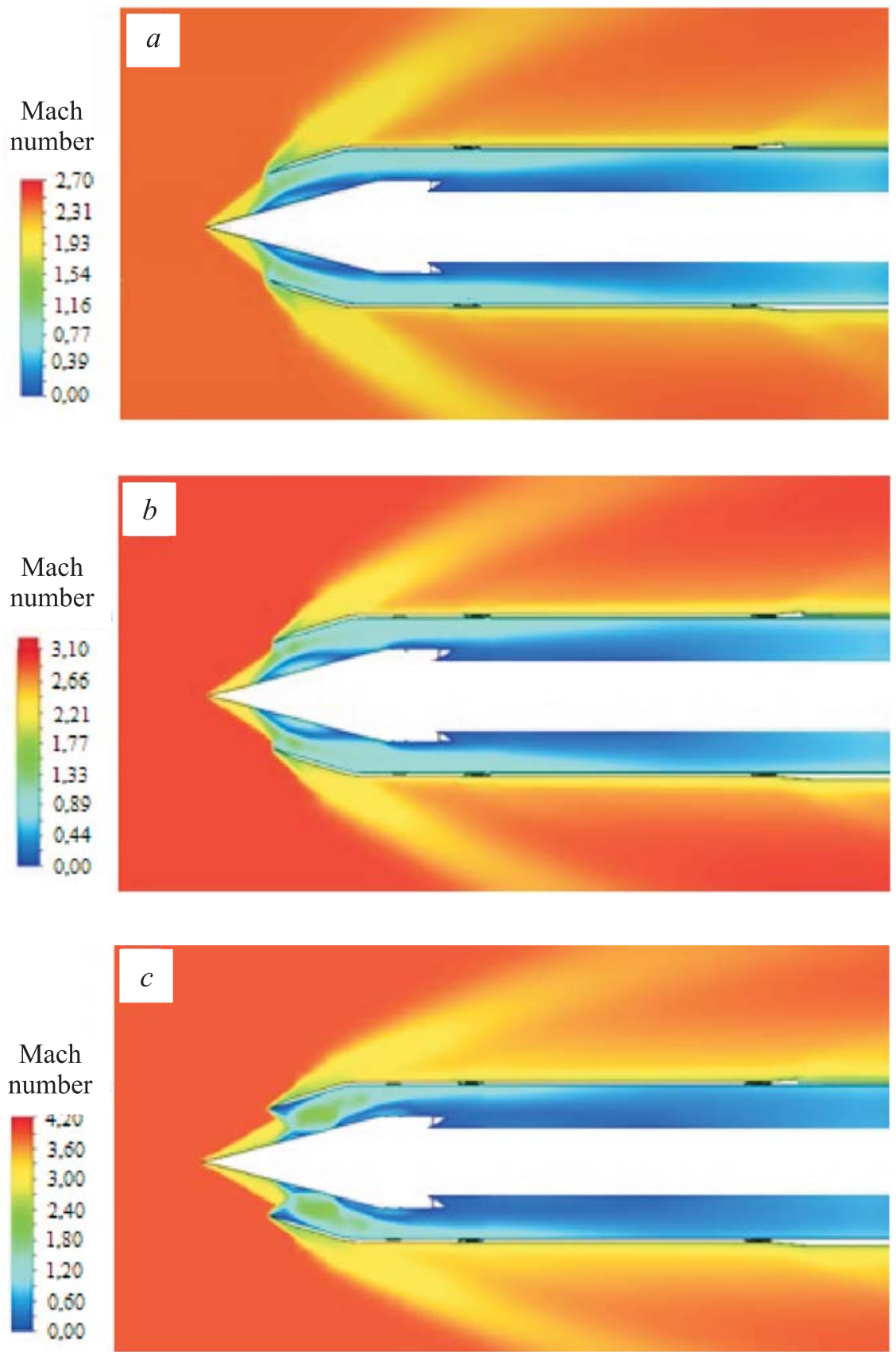

Fig. 6. Examples of the flow diagrams in the ramjet model: $a$ are $\mathrm{M}=2.5$, heat addition of $16 \mathrm{MW}$ ( Iout $\left._{\text {I }} / \mathrm{I}_{\text {in }}=6.62\right) ; b$ are $\mathrm{M}=3$, heat addition of $25 \mathrm{MW}$ $\left(I_{\text {out }} / I_{\text {in }}=6.56\right) ; c$ are $\mathrm{M}=4$, heat addition of $40 \mathrm{MW}\left(I_{\text {out }} / I_{\text {in }}=5.43\right)$ 
ANSYS modelling system uses finite volume method and stationary Navier - Stokes equations. The tool automatically analyses the geometry of the body under consideration and creates the grid on the body itself as well as in the volume of interest. The grid is then being optimized; in the areas close to the body and in the areas of high gradients the grid can contain up to 2500000 cells. The turbulence was implemented using the $(k-\varepsilon)$-model. Figure 6 features examples of Mach number distribution in the ramjet channel at different heat addition obtained by modelling.

Based on the calculated values of the flow and the mass-averaged total pressure in the jet engine channel, the flow rate coefficient and the total pressure recovery coefficient were calculated for different throttling values (determined by flow heating in the combustion chamber).

Throttling characteristics. Taking together the direct measurements of the total pressure and the flow rate in measurement cross-section, one may get the throttling characteristic of the air inlet in question. Throttling characteristic is the ratio of the total pressure recovery coefficient and the flow rate coefficient at the known Mach number for the approach flow. The throttling characteristics of the multi-wedge air inlet at various Mach numbers is pictured on the Fig. 7.
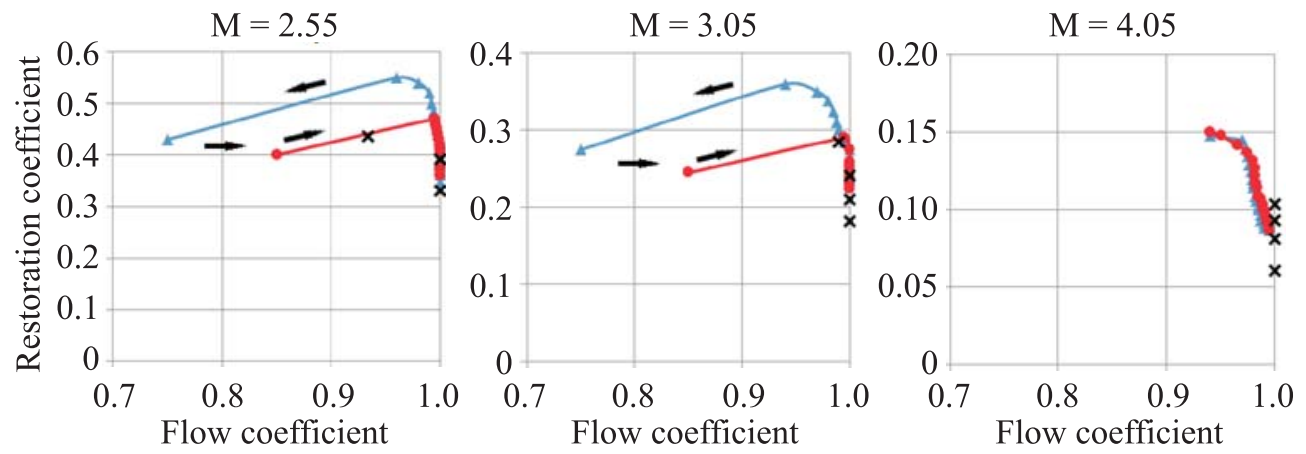

Fig. 7. Throttling characteristics of the multi-wedge frontal air inlet:

$\leftrightarrow$ are forward movement of the throttle; $\bullet$ are reverse movement of the throttle;

$x$ are calculation

The arrows show the direction of the throttle's movement. The dissimilarities between the throttling characteristics of the forward movement and the reverse movement of the blocking cone show the existence of a hysteresis when the flow restores from the surging mode. The crosses show the computational results for the air movement in the air inlet at different heat addition from the combustion chamber. The evident convergence between the computational and the experimental data both for the pressure recovery coefficient 
D.A. Vnuchkov, V.I. Zvegintsev, D.G. Nalivaichenko

and the flow rate coefficient shows that the Reynolds number has low influence in the range under consideration.

Conclusion. 1. A new and original method for measurement of throttling characteristics of air inlets using a wind tunnel of stationary action and continuous supervision of the flow characteristics in the measurement section was suggested.

2. Experimental research into the throttling characteristics of a novel axissymmetrical air inlet with multi-wedge central body (star-shaped crosssection), at Mach numbers in range from $\mathrm{M}=2.5$ to $\mathrm{M}=4$ was performed.

3. The results of the $3 \mathrm{D}$ numerical simulation of the flow in the air inlet under consideration with heat addition from the combustion chamber converge with the experimental data.

Translated by O. Kirovskii

\section{REFERENCES}

[1] Shikhman Yu.M., Vinogradov V.A., Kashkin Yu.F. Vozdukhozaborniki GPVRD [Air intakes for scramjets]. Moscow, TsIAM Publ., 2005.

[2] Gutov B.I., Zatoloka V.V. O klasse konvergentnykh vozdukhozabornikov s ploskimi stenkami i strelovidnost'yu perednego i zadnego uchastkov kromki vozdukhozabornikov [A class of convergent air inlets with plane walls and sweep of the leading and trailing inlet lips]. Fizicheskaya gazodinamika (Aerofizicheskie issledovaniya). Sb. trudov ITPM SO AN SSSR [Physical Gas-Dynamics (Aerophysical Studies): Proc. ITPM SO AN SSSR]. Novosibirsk, ITPM SO AN SSSR Publ., 1976, pp. 57-61 (in Russ.).

[3] Gun'ko Yu.P., Zatoloka V.V., Yudintsev Yu.N. O klasse form giperzvukovykh letatel'nykh apparatov s konvergentnymi vozdukhozabornikami, postroennykh iz prostranstvennykh kombinatsiy V-obraznykh tel [A shape class of hypersonic aircraft with convergent air inlets constructed from 3D combinations of $\mathrm{V}$-shaped bodies]. Issledovaniya po giperzvukovoy aerodinamike. Sb. trudov ITPM SO AN SSSR [Studies in field of hypersonic aerodynamics. Proc. ITPM SO AN SSSR]. Novosibirsk, ITPM SO AN SSSR Publ., 1978, pp. 68-84 (in Russ.).

[4] Vnuchkov D.A., Zvegintsev V.I., Nalivaychenko D.G. Design of cylindrical air inlets for high flight speeds from a combination of plane flows. Thermophys. Aeromech., 2013, vol. 20, no. 1, pp. 65-77. DOI: 10.1134/S086986431301006X

[5] Vnuchkov D.A., Zvegintsev V.I., Nalivaychenko D.G. Experimental study of a cylindrical air inlet designed on the basis of plane flows. Thermophys. Aeromech., 2014, vol. 21, no. 2, pp. 171-178. DOI: $10.1134 /$ S0869864314020048

[6] Zatoloka V.V., Kisel' G.A. Ispytaniya giperzvukovogo konvergentnogo vozdukhozabornika pri $\mathrm{M}=1,75 \ldots 6$ [Tests of a hypersonic convergent air inlet at $\mathrm{M}=1.75-6$ ]. Voprosy gazovoy dinamiki. Aerofizicheskie issledovaniya. Sb. trudov ITPM SO AN SSSR [Problems in gas dynamics. Aerophysical studies. Proc. ITPM SO AN SSSR]. Novosibirsk, ITPM SO AN SSSR Publ., 1975, pp. 236-238 (in Russ.). 
Investigation of Throttling Characteristics in Supersonic Polyclinic Inlet

[7] Gun'ko Yu.P. Osobennosti aerometrii raskhodno-silovykh kharakteristik modeley pri sverkhzvukovykh skorostyakh [Features of power consumption characteristics aerometry of models at supersonic speed]. Metody i tekhnika aerofizicheskikh issledovaniy. Sb. trudov ITPM SO AN SSSR [Methods and technique of aerophysical research. Proc. ITPM SO AN SSSR]. Novosibirsk, ITPM SO AN SSSR Publ., 1978, pp. 85-96 (in Russ.).

[8] Goonko Yu.P. Aerodynamic experimentation with ducted models as applied to hypersonic air-breathing vehicles. Exp. Fluids, 1999, vol. 27, no. 3, pp. 219-234.

DOI: $10.1007 / \mathrm{s} 003480050347$

[9] Gun'ko Yu.P. Eksperimental'noe sravnenie metodik opredeleniya pnevmometricheskimi sposobami summarnogo raskhoda struy sverkhzvukovykh neravnomernykh potokov [Experimental comparison of the methods for determining total flow rate of supersonic uneven flows by pneumometric methods]. Novosibirsk, ITPM SO AN SSSR Publ., 1981.

[10] Zvegintsev V.I. Gazodinamicheskie ustanovki kratkovremennogo deystviya. Ch. 1. Ustanovki dlya nauchnykh issledovaniy [Short-duration gas-dynamic facilities. P. 1. Facilities for scientific research]. Novosibirsk, Parallel' Publ., 2014.

Vnuchkov D.A. - Research Assistant, Khristianovich Institute of Theoretical and Applied Mechanics, Siberian Branch of Russian Academy of Sciences (Institutskaya ul. 4/1, Novosibirsk, 630090 Russian Federation).

Zvegintsev V.I. - Dr. Sc. (Eng.), Senior Research Fellow, Khristianovich Institute of Theoretical and Applied Mechanics, Siberian Branch of Russian Academy of Sciences (Institutskaya ul. 4/1, Novosibirsk, 630090 Russian Federation).

Nalivaychenko D.G. - Cand. Sc. (Eng.), Research Fellow, Khristianovich Institute of Theoretical and Applied Mechanics, Siberian Branch of Russian Academy of Sciences (Institutskaya ul. 4/1, Novosibirsk, 630090 Russian Federation).

\section{Please cite this article as:}

Vnuchkov D.A., Zvegintsev V.I., Nalivaichenko D.G. Investigation of throttling characteristics in supersonic polyclinic inlet. Herald of the Bauman Moscow State Technical University, Series Mechanical Engineering, 2019, no. 2, pp. 21-33.

DOI: 10.18698/0236-3933-2019-2-21-33 